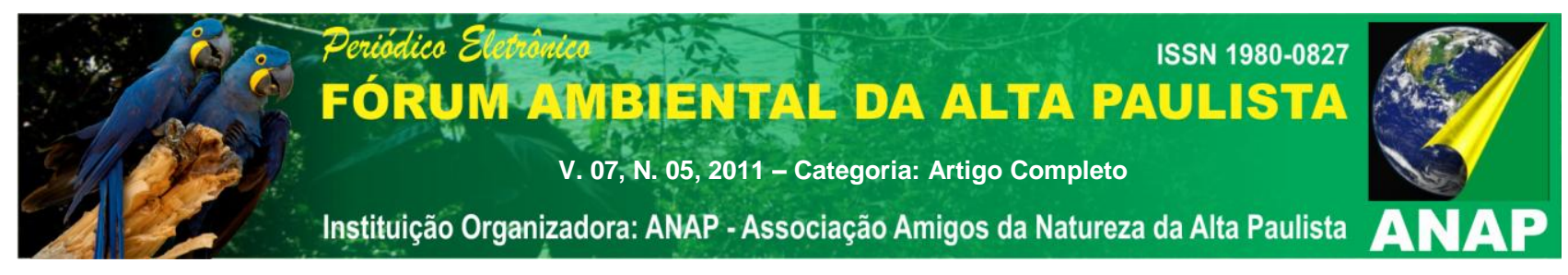

\title{
A LEI FEDERAL 9.795/99 COMO POLÍTICA PÚBLICA NA FORMAÇÃO CONTÍNUA DO PROFESSOR EM EDUCAÇÃO AMBIENTAL: SUA APLICAÇÃO COMO INSTRUMENTO DE CIDADANIA ATIVA
}

\author{
Clenícia Maria de Souza Zêba ${ }^{1}$
}

\author{
Antonio Carlos de Miranda²
}

\begin{abstract}
Resumo: Esse artigo apresenta uma discussão em relação à necessidade de acesso do professor à formação contínua em Educação Ambiental como uma política pública, na tentativa de definir indicadores que os auxiliem em decorrência da criação da Lei no 9.795/99. Nesse sentido, o estudo de caso mostra alguns elementos que apontam para um dos objetivos do nosso trabalho: analisar como se desenvolve a prática de Educação Ambiental na escola pública. Os dados foram coletados por meio de um questionário contendo perguntas abertas, e complementado por entrevista semi-estruturada, interpretados conforme os pressupostos da análise de conteúdo. Constatamos através das respostas dos sujeitos da pesquisa, um entendimento restrito do que seja Educação Ambiental, uma vez que nas respostas predominaram os aspectos conservacionistas da Educação Ambiental. Em relação à categoria práticas pedagógicas em Educação Ambiental, verificou-se que os professores desenvolvem essas práticas de maneira pontual com características tecnicistas. Com relação à categoria formação contínua do professor em Educação Ambiental, verificou-se que não há ações ordenatórias a esse respeito. Portanto, o município não segue as orientações expressas na legislação nacional que atribui a ele, a responsabilidade da oferta destas ações. Para a superação desta dicotomia, apontamos para a necessidade do direito do professor à formação contínua em Educação Ambiental, prevista na Lei 9.795/99, que deverá constar como item no Projeto Político Pedagógico da escola, e a produção de uma cartilha educativa, como material de apoio didático para os professores, que poderá ser implantada na rede pública municipal.
\end{abstract}

Palavras-chave: ambiente; educação ambiental; formação contínua em educação ambiental.

\section{1 - INTRODUÇÃO}

\footnotetext{
${ }^{1}$ Advogada, Mestre (UNIPLI), Pedagoga da Secretaria Municipal de Educação de Duque de Caxias/RJ. clenicia@hotmail.com

${ }^{2}$ Professor do Programa de Pós Graduação Stricto Sensu - UNIPLI. mirantam@ig.com.br
} 


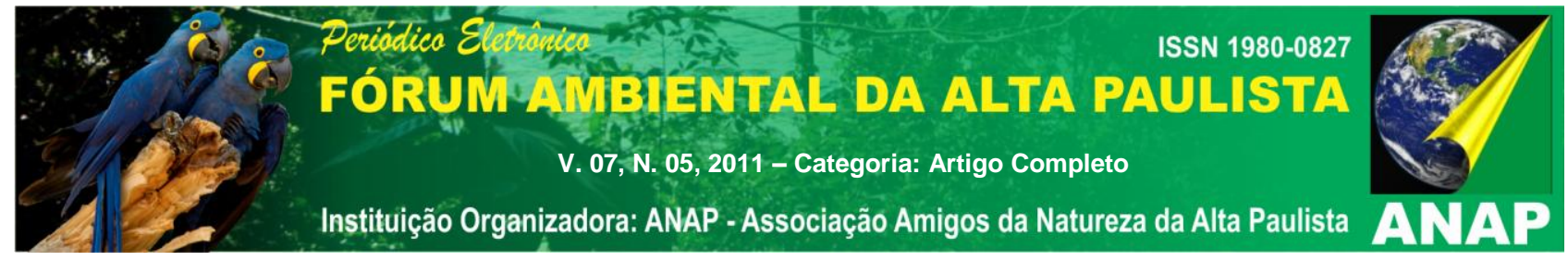

Embora conheça a existência de leis para crimes ambientais, o ser humano continua degradando o ambiente, sem a preocupação com a conservação do planeta e da sua biodiversidade. Diariamente, assistimos à vertiginosa agressão à natureza através das devastações das matas, da dilapidação dos recursos naturais, do consumo desenfreado, do acúmulo de resíduos em lixões, a contaminação de recursos hídricos e, da falta de saneamento básico nas cidades, do descaso dos governantes com a educação da população e com a justiça sócio-ambiental. É de grande valia, que o ser humano, sumarize suas atitudes. Tendo como ponto de partida esse quadro de crise causador da ação antrópica do homem ao planeta, e como forma de colaborar com o desenvolvimento de posturas pró-ativas que favoreçam o estabelecimento de uma política pública onde prevaleça a justiça sócio-ambiental. Este artigo abordou a necessidade de engendrar a dimensão ambiental no Projeto Político Pedagógico da escola, através da formação contínua do professor em Educação Ambiental, como recomenda a legislação. Como concluiu Vernier (1994), nem as leis, nem as multas ambientais obrigam os cidadãos a respeitarem o ambiente, se esse respeito, espontâneo, não lhes for passado através da educação. Assim, podemos considerar que o termo 'ambiental' que completa a educação refere-se à necessidade, colocada pela crise ambiental, de trazer para os processos educativos a tematização do ambiente.

A Educação Ambiental insere-se nas políticas públicas do Estado brasileiro de ambas as formas, como crescimento horizontal (quantitativo) e vertical (qualitativo), pois enquanto no âmbito do MEC pode ser entendida como uma estratégia de incremento da educação pública, do Ministério do Meio Ambiente é uma função de Estado totalmente nova. Uma política pública representa a organização da ação do Estado para a solução de um problema ou atendimento de uma demanda específica da sociedade. Razão pela qual socializar o conhecimento vem a ser uma ação política, pois em toda sociedade que se democratiza surge a necessidade de difundir o conhecimento às diferentes camadas sociais. A Educação Ambiental, não visa "conscientizar" as pessoas, como a maioria diz, reproduzindo um discurso sem fundamentação crítica da significação política da palavra, 


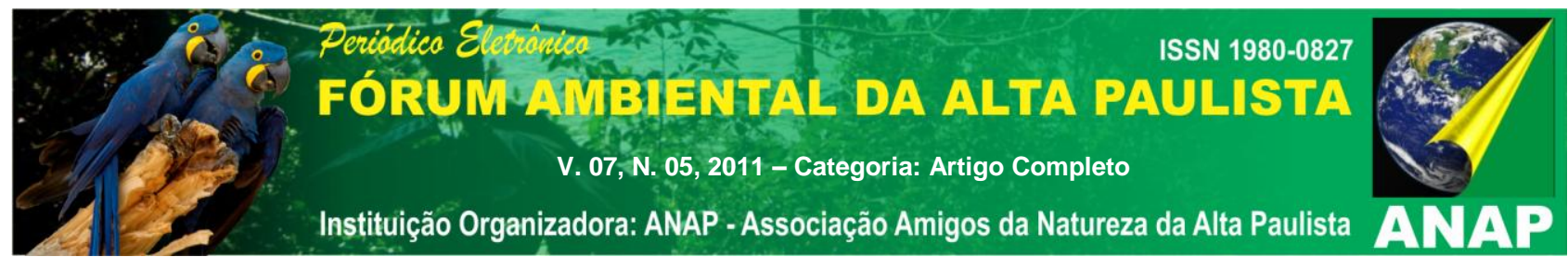

inserida no pensamento de Paulo Freire. Compartilhando da mesma premissa, Bordieu (1996) acredita que se fala demais em "consciência". O mundo social não funciona somente em termos de consciência, mas também de práticas. Portanto, o papel do Estado na política pública da educação ambiental poderá ser subsidiário e definido por meio de uma demanda da sociedade, numa idéia mais consensual, enquadra-se no que preconiza a Lei 9.795/99. Portanto, a análise da lei demonstra a transversalidade da educação ambiental que exige transformações na metodologia de ensino das escolas públicas que implica em uma formação contínua dos professores. A prática de um professor crítico reflexivo não diminui a desigualdade social gerada pelo sistema educacional, ainda tradicional ou tecnicista, mas encaminha o discente para construir uma cidadania ativa, reivindicando a justiça sócio-ambiental, sendo esta prática políticapedagógica um dos fundamentos da educação ambiental.

Vale lembrar, ainda, que a promoção da consciência crítica, propiciando novos valores; o fornecimento de conhecimentos técnicos que levam à mudança de atitude e comportamentos frente ao ambiente; e a participação de grupos sociais e indivíduos na gestão do ambiente podem ser alcançados através do conhecimento das leis ambientais, uma vez que a educação ambiental possui enfoque claramente multi, interdisciplinar e transdisciplinar, que permite não só ações individuais e coletivas, mas também ações estatais, ou seja, impostas pelo Poder Público.

\section{DESENVOLVIMENTO}

\subsection{O Traçado Metodológico}

O presente artigo traz um estudo a partir do tema: A Lei Federal 9.795/99 como Política Pública na Formação Contínua do Professor em Educação Ambiental, sua aplicação como instrumento de cidadania ativa na escola Municipal J. S. P. Parte da hipótese de que as práticas pedagógicas dos professores em Educação Ambiental são suficientes para interferir na mudança do comportamento dos escolares, e 


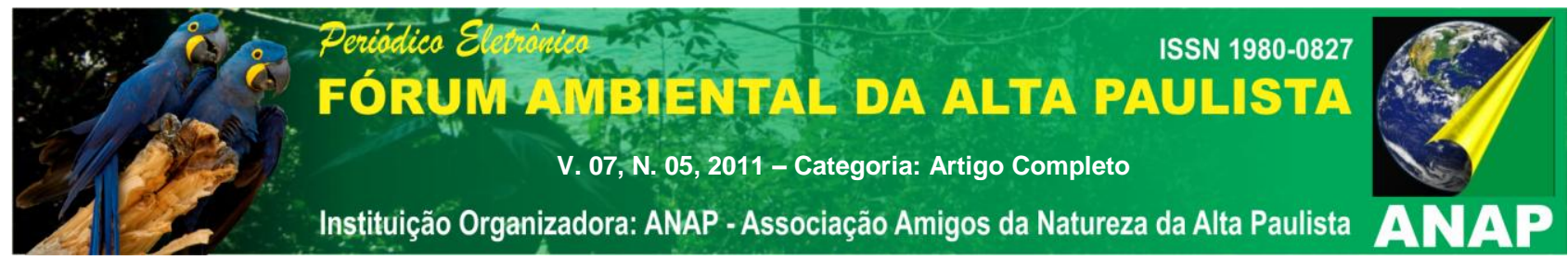

consequentemente, na realidade da comunidade. Essas práticas pedagógicas são suficientes para entenderem a transversalidade da Educação Ambiental, e tenham acesso a formação contínua em Educação Ambiental. Assim, a relevância do presente trabalho decorre da possibilidade de se verificar, pela análise comparada entre o que prevê a Lei de Educação Ambiental e o que ocorre na prática da escola, qual a distância existente entre o jurídico e o social. Propõem-se por meio deste, alguns questionamentos levantados como parte da problemática, tais como: Analisar as concepções dos docentes que lecionam nas classes iniciais do ensino fundamental da escola pública, segundo sua formação sobre: Educação Ambiental? Transversalidade da Educação Ambiental? Prática pedagógica em relação ao ambiente? Acesso à formação contínua em Educação Ambiental?

Embora possamos descrever diversas abordagens de práticas pedagógicas em Educação Ambiental, e da formação contínua de professores, levamos o nosso olhar para os conceitos a que pontua como fundamentação teórica como, Reigota (2002), Freire (2002), Nóvoa (1995), Demo (1994), Morin (2005), Carvalho (2002), entre outros, que tratam das discussões acerca desses processos como variável decisiva para a compreensão do fenômeno educativo ambiental. Por se tratar de um estudo de caso, os procedimentos metodológicos adotados para a realização deste trabalho fundamentam-se em duas modalidades de pesquisa: a) Pesquisa Documental: por meio de consultas a livros, artigos, leis, estatutos, regulamentos, decretos e outras fontes necessárias; b) Pesquisa de Campo: sustentada por aplicação de questionário aberto e entrevista semiestruturada. Os sujeitos da pesquisa são oito docentes que lecionam nas classes iniciais do ensino fundamental, da Instituição citada. Dessa forma, foram definidas, a priori, quais categorias serviriam inicialmente como análises das respostas em sua totalidade. Como categorias básicas ou simples foram adotadas: 1a - Educação Ambiental, Prática pedagógica em Educação Ambiental, $2^{\underline{a}}$ - formação contínua em Educação Ambiental no município. Com relação à metodologia de análise, adotou-se a análise de conteúdos (GOMES, 2003). A pesquisa de campo foi desenvolvida em três momentos. No primeiro momento, realizamos uma análise preliminar do Projeto Político Pedagógico da escola (cenário da pesquisa), sob o olhar da legislação. No segundo 


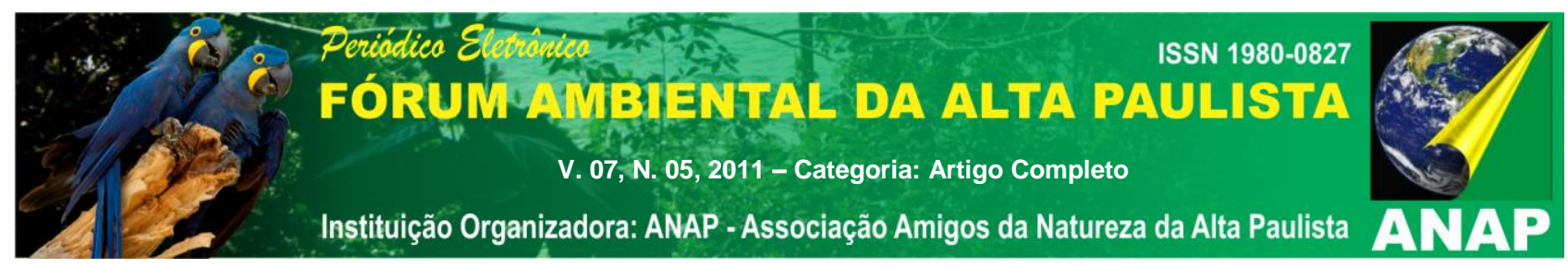

momento, realizamos um questionário e no terceiro momento uma entrevista com os professores da Escola Municipal J. S. P.

\subsection{Referencial Teórico}

Inicialmente, ao analisar a lei 9.795/99 encontram-se, principalmente nos Artigos 8응

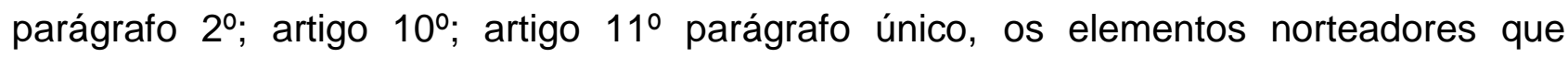
legitimam a formação contínua do professor em educação ambiental.

O artigo $8^{\circ}$ parágrafo $2^{\circ}$ da lei afirma:

Art. 8. A capacitação de recursos humanos voltar-se-á para: I - a incorporação da dimensão ambiental na formação, especialização e atualização dos educadores de todos os níveis e modalidade de ensino; II - a incorporação da dimensão ambiental na formação, especialização e atualização dos profissionais de todas as áreas;

Art. 10. A educação ambiental será desenvolvida como prática educativa integrada, contínua e permanente em todos os níveis e modalidade do ensino formal.

Art.11. A dimensão ambiental deve constar dos currículos de formação de professores, em todos os níveis e em todas as disciplinas. Parágrafo único. Os professores em suas áreas de atuação, com o propósito de atender adequadamente ao cumprimento dos princípios e objetivos da Política Nacional de Educação Ambiental.

A lei fornece indicações de como a Educação Ambiental poderá ser implantada no Brasil, quando versa em seu art. $8^{\circ}$, que se deve "capacitação de recursos humanos", entre outros aspectos, e, neste mesmo artigo, no parágrafo $2^{\circ}$, quando versa que a capacitação voltar-se-á para a formação, especialização e atualização dos educadores de todos os níveis e todas as áreas. O dispositivo legal tratado no artigo 10 impõe a prática contínua da Educação Ambiental, essa lacuna incide na qualidade da educação ambiental uma vez que a transversalidade necessita de uma fiscalização mais presente e contínua nas escolas públicas. A partir daí, as escolas públicas e privadas, ficaram obrigadas a 


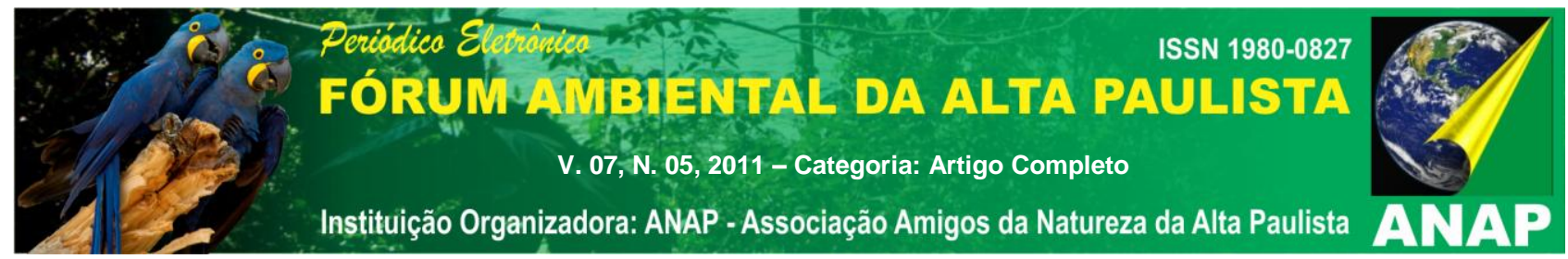

inseri-la em todas as disciplinas, em caráter formal e informal. Por sua vez o art. 11 pode ser considerado como pressuposto para caracterização da dimensão ambiental nos currículos, e em todos os níveis de ensino. Portanto, a análise da lei, demonstra a consolidação que orientam e legitimam a formação contínua do professor em educação ambiental, em suas áreas de atuação. A concretização das mudanças educacionais necessárias ao atendimento da emergente realidade social exige um professor preparado para atuar em conformidade com as propostas criadas. Apenas a motivação para a mudança que se pretende não basta; é fundamental a preparação que dê o substrato necessário à prática pretendida, sem a qual, inviabiliza-se a sua concretude, por simples incapacidade daqueles responsáveis pela sua realização. Assim, a preparação do professor para engajar-se nesse processo de construção da reflexão crítica que se deseja fomentar, a partir do projeto pedagógico, é exigência fundamental. Por sua vez, Freire (2002), discorrendo sobre os saberes necessários à prática educativa, alerta que ensinar exige competência profissional. E, relacionando-a diretamente com a segurança com que a autoridade docente se move, ressalta a importância da permanente formação docente, quando diz: "O professor que não leve a sério sua formação, que não estude, que não se esforce para estar à altura de sua tarefa não tem força moral para coordenar as atividades de sua classe. [...] a incompetência profissional desqualifica a autoridade do professor." (Freire, 2002,p.92).

É importante destacar de início, que a Carta Magna trouxe grande avanço no que toca às questões ambientais, pois foi uma das primeiras constituições do mundo a tratar do meio ambiente em capítulo próprio, o que veio a ser feito em demais países por meio de emendas, conforme lembra EDIR MIRALÉ (2004, p.121), ao referir-se às modificações nas Constituições do Chile e Panamá (1972), lugoslávia (1974), Portugal (1976), e Espanha (1978). As bases da Educação Ambiental estão expressamente insertas no corpo da Carta Magna, que através do art. $225, \S 1^{\circ}$, VI, diz que:

Art. 225. Todos têm direito ao meio ambiente ecologicamente equilibrado, bem de uso comum do povo e essencial à sadia qualidade de vida, impondo-se ao Poder Público e à coletividade o dever de defendê-lo e preservá-lo para as presentes e futuras gerações. 


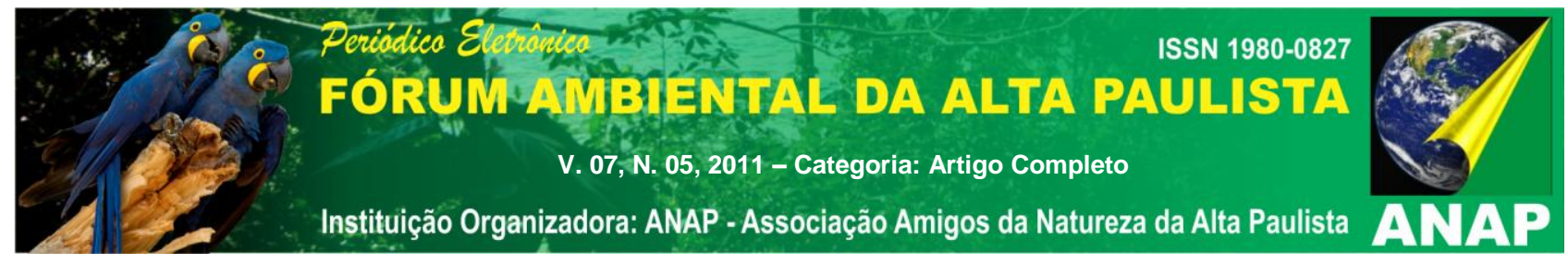

$\S 1^{\circ}$ Para assegurar a efetividade desse direito, incumbe ao Poder Público: $[\ldots]$

VI - promover a Educação Ambiental em todos os níveis de ensino e a conscientização pública para a preservação do meio ambiente;

Vê-se, portanto, que as normas de Direito Ambiental, nacionais e internacionais, cada vez mais reconhecem direitos próprios da natureza, independentes do valor que esta possa ter para o ser humano. Esse pensamento, aliás, encontra guarida nas disposições constantes da Resolução 37/7, de 28/10/1982, proclamada pela Assembléia Geral da ONU, que estipulam que "toda a forma de vida é única e merece ser respeitada, qualquer que seja a sua utilidade para o homem, e, com finalidade de reconhecer aos outros organismos vivos este direito, o homem deve se guiar por um código moral de ação". Isso, todavia, não quer dizer que a pretensa superação do antropocentrismo radical implique uma modalidade de irracionalismo, capaz de colocar em pé de igualdade o homem e os demais seres vivos, rebaixando o valor da vida humana para transformá-la em algo sem valor em si próprio. A educação ambiental por meio das leis deve buscar o reconhecimento do ser humano como parte integrante da natureza, que não tenta subjugá-la, mas que pretende estabelecer a normatividade da harmonização entre todos os componentes do mundo natural culturalizado, no qual, a todas as luzes, o ser humano desempenha papel essencial, como ensina Antunes (2001). A partir daí, a educação ambiental passa a ser pensada de um novo ângulo, como um projeto transformador, crítico e político, preparando o indivíduo mediante a compreensão dos principais problemas do mundo contemporâneo, possibilitando-lhe conhecimentos técnicos e qualificações necessárias para desempenhar uma função produtiva, com vistas a melhorar a vida e proteger o meio ambiente. A mudança da visão naturalista da educação ambiental, de admiração da paisagem natural, para a concepção de uma sociedade democrática e socialmente justa passa, necessariamente, pela idéia de que a sociedade ambientalmente equilibrada só teria espaço com a busca de uma sociedade democrática, servindo a lei como instrumento hábil a concretizar o processo de educação ambiental.

Da lição de SILVA (2002), extrai-se que a crescente intensidade dos desastres ecológicos despertou a consciência ambientalista ou a consciência ecológica por toda a 


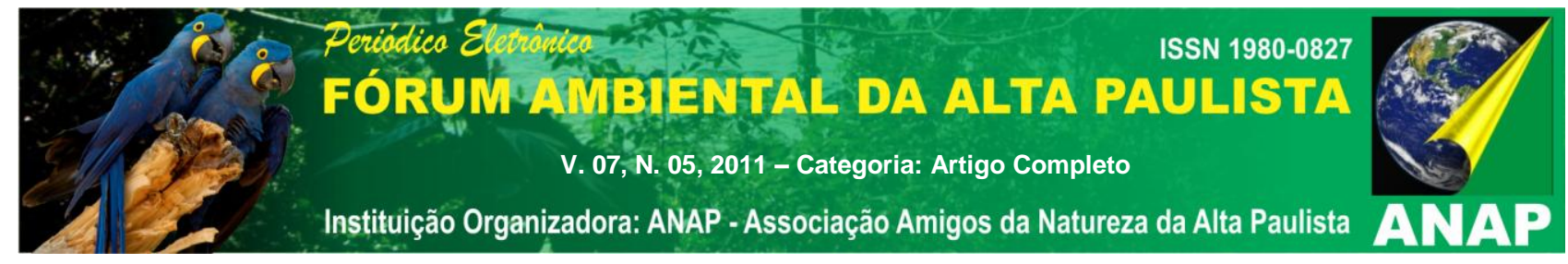

parte, chamando a atenção para o problema da degradação e destruição do meio ambiente, natural e cultural, de forma sufocante. Daí proveio a necessidade da proteção jurídica ao meio ambiente, com o combate pela lei de todas as formas de perturbação da qualidade do meio ambiente e do equilíbrio ecológico, de onde foi surgindo uma legislação ambiental em todos os países. Nessa perspectiva, as leis ambientais, entendidas como "Direito do desenvolvimento sustentável" pela moderna doutrina norteamericana e canadense, tem como base não a tentativa de corrigir impactos que já ocorreram, mas a tentativa de ações preventivas (e não ações compensatórias ou mitigatórias), imprimindo um papel notadamente educativo, na busca de uma conscientização ao meio ambiente equilibrado. A correta compreensão das leis ambientais no Brasil é um caminho que pode contribuir para o desenvolvimento sustentável.

O direito à educação e o direito ao ambiente, quando violados, podem acarretar danos irreparáveis ao ser humano e ao próprio ambiente. Os direitos da personalidade embora sejam preocupações antigas, são direitos subjetivos, que têm como objeto os bens e valores essenciais da pessoa, no seu aspecto físico, direito à vida e ao próprio corpo, no aspecto intelectual, o direito à liberdade de pensamento, o direito de exigir de terceiros o respeito a estes direitos. Assim é que, a par dos direitos e deveres individuais e coletivos, elencados no referido artigo $5^{\circ}$ da Constituição Federal, acrescentou 0 legislador constituinte, no caput do artigo 225, um novo direito humano fundamental, direcionado ao desfrute de adequadas condições de vida em um ambiente saudável ou, na dicção da lei, "ecologicamente equilibrado". Concordamos com Amaral (1993:24), quando conclui: "o direito ao ambiente é um direito subjetivo fundamental, de natureza personalíssima, e tendo como função conservar um ambiente sadio e ecologicamente equilibrado em favor do titular e de terceiros, inclusive de geração futura". Em suma, o meio ambiente ecologicamente equilibrado é condição para o desenvolvimento saudável da vida humana. Enfim, justifica-se a proteção jurídica aos direitos da personalidade nos contextos ambiental e educacional, uma vez que a educação é uma necessidade básica do ser humano. Pensamos que a correta compreensão das leis ambientais no Brasil é um eficaz instrumento da política de educação ambiental. Além disso, como ensina Dias 


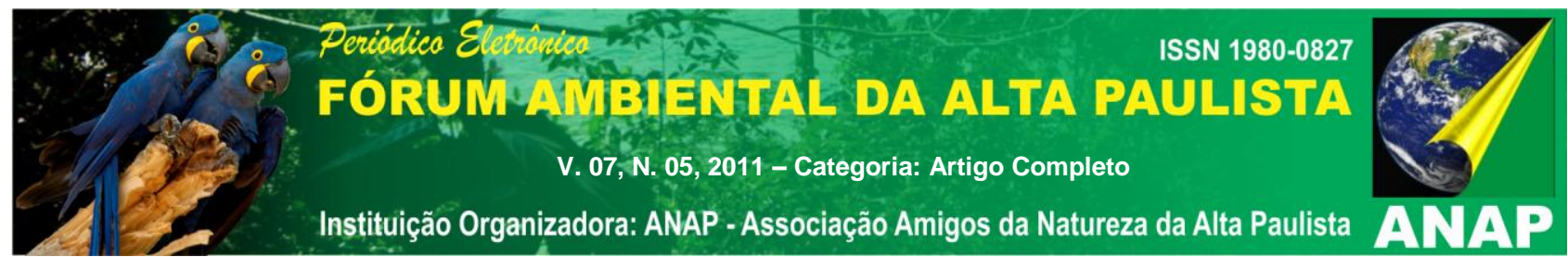

(1994), "a chave para o desenvolvimento é a participação, a organização, a educação e o fortalecimento das pessoas". Isso, pois o desenvolvimento sustentado não é centrado na produção, mas sim nas pessoas. Assim, tendo a legislação ambiental importante caráter educativo na prevenção da degradação ambiental e na busca do desenvolvimento sustentável, a educação ambiental deve integrar o conhecimento e o respeito a essas leis, buscando a construção de agendas ambientais por meio de um processo participativo que possibilite o aprendizado das mais diversas questões relacionadas ao meio ambiente.

\subsection{Análise e Discussão}

A seguir, sob o foco dos pressupostos apresentados, investigamos alguns temas envolvendo a conceituação dos professores (sujeitos da pesquisa) acerca das seguintes questões:

a) O que entendem por educação ambiental? Escolhemos dois tipos de resposta que nos pareceu serem as mais emblemáticas: $O$ primeiro professor respondeu: "Aprender e desenvolver meios de preservar e aproveitar o ambiente em que se vive, através dessa disciplina obrigatória para que todos os alunos tenham uma base sólida". $\mathrm{O}$ segundo professor respondeu: "A educação ambiental é a sensibilização formalizada para proteção ambiental e conservação da natureza". A resposta do primeiro docente, confere a educação ambiental como uma disciplina isolada, explicitando uma leitura conservadora. A resposta do segundo docente, é singular porque a educação ambiental não tem só a função de conscientizar, mas ressalta o aspecto "ativo" ou "comportamental" (REIGOTA, 2001). De modo complementar, Loureiro (2004, p. 31) conceitua a educação ambiental como, "em síntese, uma práxis educativa que é em si cultural e informativa, mas que fundamentalmente política, formativa e emancipatória, portanto, transformadora das relações sociais existentes". Nesse sentido, Gutiérrez-Perez ressalta que a educação ambiental não é uma tarefa inocente isenta de intencionalidade e propósitos, nem se trata de ensinar às crianças como o mundo anda mal, nem tampouco ocultá-lo. O acúmulo 
de conflitos, valores, culturas e idiossincrasias que se cruzam nessa parcela de responsabilidade, atribuem ao ambiental um valor superestimado de complexidade epistemológica e um status disciplinar de singular riqueza, pois nele se encontra uma diversidade de interesses contrapostos, de ideologias contrárias, de pressupostos filosóficos divergentes, de éticas díspares e de práticas cotidianas muito desiguais e variadas. (2005, p. 180). Isso se opõe com a educação ambiental caracterizada por Morales (2007), que afirma, que durante algum tempo, esta se restringiu a cumprir seu papel na perspectiva preservacionista, o que implicou no reducionismo refletido nas práticas pontuais, relacionadas às datas comemorativas, ao desenvolvimento de hortas e jardins, à reciclagem de lixo, entre outras diversas atividades.

b) Quais os aspectos da prática em Educação Ambiental que privilegia? A resposta de quatro professores nos chama atenção porque não privilegia a transmissão de conhecimentos, eles chamam a atenção para a sustentabilidade. Os outros quatro docentes descrevem atividades que, apresentando variações de temas, inserem-se um contexto de Educação Ambiental. Nesse contexto, segundo Reigota (1998), a educação ambiental para a sustentabilidade aponta propostas pedagógicas centradas na conscientização, mudança de comportamento, desenvolvimento de competências, capacidade de avaliação e participação dos escolares. O principal eixo da atuação da educação ambiental deve buscar a solidariedade, a igualdade e o respeito, baseadas em práticas interativas, consubstanciando no objetivo de criar novas atitudes e comportamento diante do consumo. Em relação à inserção da Educação Ambiental no currículo, todos os professores afirmaram que esta é necessária para a sensibilização e conscientização não somente dos alunos, mas também da comunidade local em relação aos problemas ambientais. Porém, divergiram quanto à forma como esta deve ser apresentada. Para alguns, sua inserção deve ocorrer de forma diluída no currículo, enquanto que para outros esta deve ser uma disciplina isolada: 
c) Como entende a Transversalidade da Educação Ambiental? Os oito professores responderam que a transversalidade facilita a construção das inter-relações dos fenômenos sócio-ambiental. No entanto, há uma incoerência destas respostas com as anteriores, no que diz respeito ao conceito de Educação Ambiental e Práticas Pedagógicas em educação ambiental. Este resultado não implica dizer que a transversalidade da Educação Ambiental está sendo devidamente praticada na escola, mesmo diante de todo aparato legal de que dispõe a lei. Para Gallo (2000:33), a transversalidade está relacionada ao reconhecimento da multiplicidade de saberes enquanto exige transformações na metodologia de ensino das escolas públicas que implica na motivação dos professores, somada à capacitação, treinamento. Transversalidade é a qualidade de transversal, assim prolongada na Educação Ambiental como os conteúdos de ambiente serão integrados ao currículo através do que se chama transversalidade, isto é, serão tratados nas áreas de conhecimento de modo a penetrar toda a prática educativa e, ao mesmo tempo, criar uma visão global e abrangente da questão ambiental. A transversalidade da Educação Ambiental exige transformações na metodologia de ensino das escolas públicas que implica na formação contínua de professores.

d) Tem conhecimento de Formação Contínua em Educação Ambiental no município? A maioria dos professores respondeu que não existe a formação no município. Percebe-se que o dispositivo legal que determina a formação complementar dos professores em Educação Ambiental está comprometida. Ademais, para uma política já definida como compulsória indica que alguns corretivos devem ser feitos. Na prática pedagógica das escolas ocorre um grande distanciamento entre o que concerne à lei e a jornada do dia-a-dia da escola. Nesse sentido, não basta que a Educação Ambiental esteja assegurada na legislação para que seja efetivada. Sua eficácia depende do conhecimento destas garantias, e também, da tomada de consciência da necessidade de se lutar por elas. Entendemos que o não cumprimento de uma obrigação de fazer do Estado, que determina a formação contínua em Educação Ambiental para os professores, trata-se, em verdade, de assunto relevante, que precisa ser inserido na pauta de 


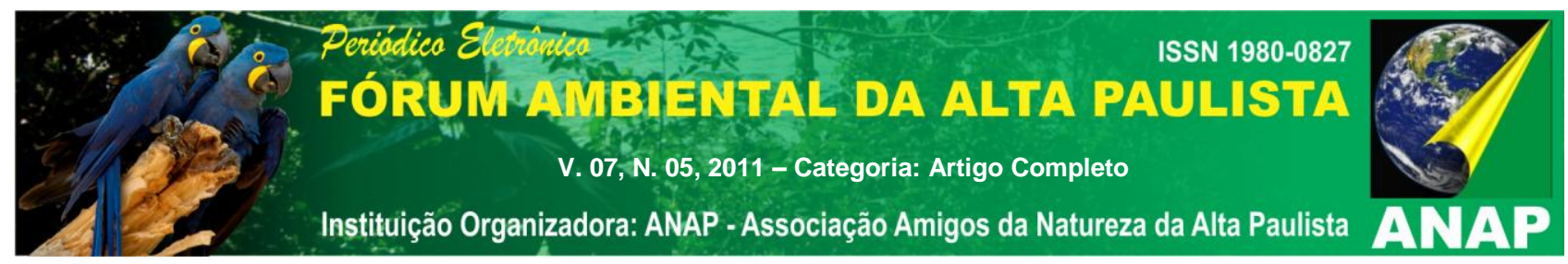

prioridades do Município, para que as políticas públicas municipais cumpram com os ditames emanados não apenas da referida lei, mas também da Constituição Federal. Não adianta o aparato legal sem conscientização da sociedade, pois esta detém legitimidade social. Reconhecer o direito da formação contínua em educação ambiental, não apenas na lei, mas na sensibilização da construção coletiva, na busca da cidadania ativa, possibilita reflexão e questionamentos das políticas públicas de educação.

e) Existem critérios e incentivos no município para a formação contínua em EA para os professores? Escolhemos dois tipos de resposta que nos pareceu serem as mais emblemáticas: O primeiro professor respondeu: "Não sei responder, porque até o momento não tive nenhuma formação em EA, nas escolas que já trabalhei." $O$ segundo professor respondeu:" Para ser franco, não há incentivos e critérios são as indicações que a direção ou até mesmo a SME faz para que alguns professores participem em algum momento de cursinhos de alfabetização, entre outros, mas de EA, aqui nessa escola, ou em outra não existe".

As respostas dos docentes indicam que embora a formação contínua esteja fundamentada nos princípios defendidos na lei de Educação Ambiental, o município não investe na formação contínua de professores. Hoje a realidade vem impondo novos caminhos ao poder público, entendendo a formação em serviço como um direito do professor e dever do Estado e, acima de tudo, com uma necessidade vital para o desenvolvimento profissional do professor. Evidentemente que não basta existir a norma, imprescindível para sua real aplicação e efetividade, como política pública. A Política Pública, assim, pode ser entendida como o "Estado em ação" (Gobert, Muller,1987 apud HÖFLING,2001), "é o Estado implantando um projeto de governo, através de programas, de ações voltadas para setores específicos da sociedade”.(HÖFLING, 2001 p.31).

Segundo Libâneo (2003), como conseqüência as Secretarias de Educação têm o dever e a responsabilidade de fazer as escolas funcionarem e, para isso, é necessário que os professores tomem conhecimento de certas normas e diretrizes, se convençam de sua legitimidade e passem a agir de acordo com as expectativas dos dirigentes. A direção 


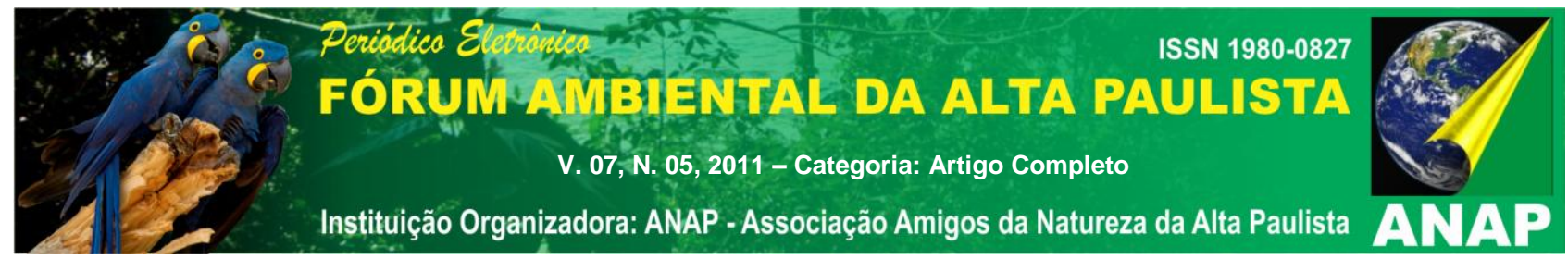

por sua vez, deve reunir o corpo docente para comunicar novas normas legais, diretrizes pedagógicas e mudanças de rotina de trabalho. A formação contínua deve estar inserida no projeto educativo da escola, hoje especificadamente o Projeto Político Pedagógico, para que os professores fiquem incentivados à adequação da realidade educacional. Nóvoa (1995: 27) faz uma reflexão em que a escola para ser eficaz deve implementar programas de formação contínua aos profissional, especialmente o pessoal docente

A competência do município em matéria de Educação Ambiental está firmado no artigo 16 da Lei n 9.795/99 que diz: " os estados, o Distrito Federal e os municípios, na esfera de sua competência e nas áreas de sua jurisdição definirão diretrizes, normas e critérios para a educação ambiental, respeitando os princípios e objetivos da Política Nacional de Educação Ambiental". As políticas de formação exigem redefinição das formas de organização do próprio órgão gestor e do município, para que essas políticas possam atender as demandas sociais em uma sociedade em constante mudança ambiental. A formação contínua deve estar inserida no projeto educativo da escola. Uma política é pública quando é de domínio público. Os projetos e ações que visam concretizar uma política pública devem igualmente ser objeto de análise, críticas e debates; para tanto, sua fundamentação teórica, seus objetivos reais, os resultados esperados e critérios de avaliação, sua forma de implantação, devem ser também de domínio público.

É preciso que seja incentivado na escola o desencadeamento de reflexos que levem o docente a compreender as questões ambientais para além de suas dimensões físicas, químicas e biológicas. Deve haver, na escola, um entendimento sócio-político das questões ambientais, o que exige a formação de uma consciência ambiental porque é lá o espaço onde professores e alunos se manifestam em relação a seus direitos e deveres, exercem sua cidadania. Rattner (1994:44) é enfático ao ressaltar que são, principalmente, as opções políticas formadas pelos países em desenvolvimento e não necessariamente as novas tecnologias, que definirão o "nosso futuro comum". Para conseguir este fim, Rattner diz que as elites e, complementamos, todos que têm sob sua responsabilidade outras pessoas - município, docentes, pais etc. - terão de movimentar a população para terem ações coesas e solidárias, induzindo processos de participação e aspirações 


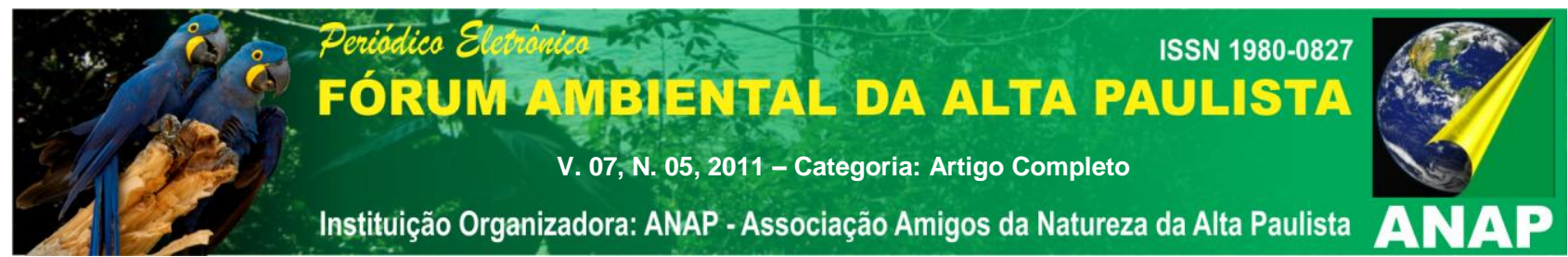

ambientais coletivas. Aí reside também o papel primordial da educação, principalmente da Educação Ambiental, de educar pessoas em sistemas de valores para um futuro comum.

\section{3 - CONCLUSÃO}

Verdade seja dita: a legislação tem sido uma alquimia desconhecida para o povo. É assunto para 'especialistas' que manipulam e desvendam os caminhos no labirinto complexo das normas jurídicas. Assim, a lei que deveria sair do povo, passa a ser atributo do Estado, que deveria realizar alguma concepção de justiça, tornase possível instrumento de dominação, que deveria regular a sociedade, passa a justificar as desigualdades (Aguiar, 1994).

$\mathrm{Na}$ leitura da Lei 9.795/99, depreende-se claramente o quanto enfatiza a importância do meio ambiente e sua contínua contextualização nos planos da educação. Em que pese a não efetividade de muitas das disposições legais, é necessário que os problemas relacionados à Educação Ambiental sejam discutidos. Dentre eles, o destaque para a transversalidade é dos mais imprescindíveis, porque enquanto todos os professores não conseguirem uma formação contínua para perceber a abrangência e importância do meio ambiente, discutindo isso com os alunos, não haverá como se falar de um vigoroso processo de conscientização.

Esse entendimento pôs em evidência a adequação do traçado metodológico escolhido, para a realização dessa pesquisa, assim como indicou os caminhos com pertinência para as indagações no questionário, e nas entrevistas, dirigidas aos sujeitos da pesquisa. Nesse sentido, não basta que a Educação Ambiental esteja assegurada na legislação para que seja efetivada. Sua eficácia depende do conhecimento destas garantias e, também, da tomada de consciência da necessidade de se lutar por elas. $A$ necessidade de novo perfil de professor emerge como reclamo da sociedade, é estabelecido pelas disposições legais, e se pretende concretizado pelo fazer educativo, 


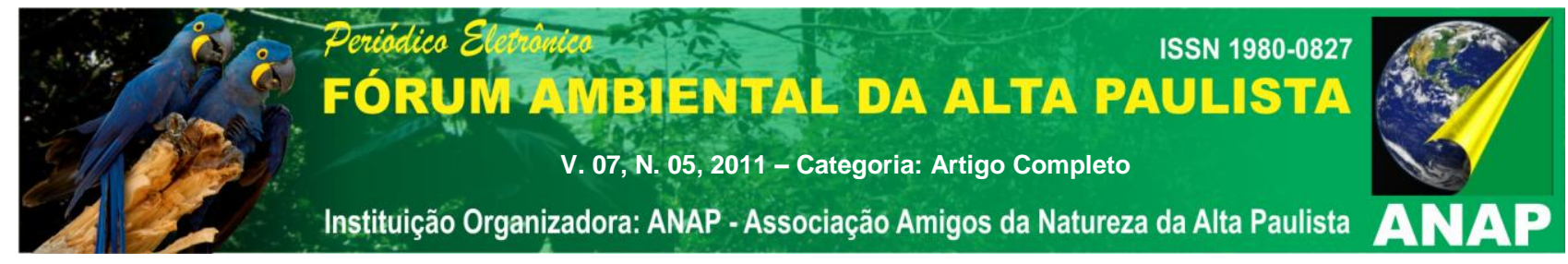

constantemente aperfeiçoado pela formação continuada. Para tanto, o papel do projeto pedagógico é fundamental. Como catalizador dos interesses coletivamente defendidos, em suas dimensões política e pedagógica mostra-se instrumento imprescindível na definição da proposta de trabalho na qual, entre outros, poderão ser traçados princípios e estratégias para a formação continuada do docente. Formação que tem papel fundamental na caracterização do processo de ensino-aprendizagem que o momento exige: calcado na construção do conhecimento a partir de diálogo com a realidade, ou seja, num processo dialético, entendido como movimento que parte do real e se eleva até a mente, mostrando a provisoriedade das coisas e das pessoas e conduzindo o sujeito a novas descobertas. Ou seja, favorecendo a construção do sujeito interdisciplinar (Barbosa, 1999). Em resumo, a nova realidade social exige autonomia intelectual, capacidade para enfrentar o novo, habilidade para lidar consigo e com o outro. E a Educação Ambiental mostra-se propiciadora da construção deste sujeito pretendido, uma vez entendida como saber dialeticamente construído, transformadora de valores e atitudes, propiciadora de nova ética visando a obtenção da qualidade de vida. Por fim, destacamos como sintetizadores do que foi tratado, dois pensamentos clássicos em educação citados por Loureiro (2004): “A educação é um ato político” (Paulo Freire) uma vez que constrói por meio das relações sociais e pedagógicas a base instrumental, a consciência política, a capacidade crítica, para intervir na História buscando a utopia social que se deseja. As informações obtidas para subsidiar este artigo foram consideradas essenciais para o esclarecimento da importância do conhecimento e aplicação da legislação em vigor como instrumento da política pública, e de cidadania ativa. E, considerando a importância que essa ocorrência pode trazer ao engajamento do docente na construção, da sua formação contínua e conseqüentemente na intervenção que se fará sentir no ambiente. Para tanto é imprescindível aprofundar investigação sobre a legislação ambiental. Desta forma, a inserção da formação contínua do professor em educação ambiental como item no Projeto Político Pedagógico da escola possibilita que os conteúdos ambientais permeiem todas as disciplinas do currículo e seja contextualizada com a realidade da comunidade. Por fim, para a superação dos entraves citados na pesquisa, apontamos para a necessidade do direito do professor à Formação 


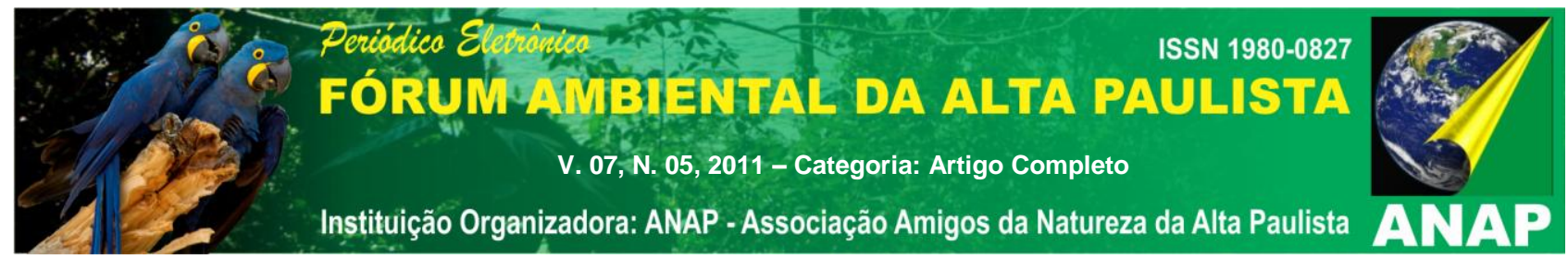

Contínua em Educação Ambiental, prevista na Lei 9.795/99, que deverá constar no Projeto Político Pedagógico da escola, e sugerimos a produção de uma cartilha educativa, como material de apoio didático para os professores, que poderá ser implantada na rede pública municipal.

\section{REFERÊNCIAS}

AGUIAR, R. A. R. Direito do meio ambiente e participação popular. Brasilia: IBAMA, 1994.

AGUIAR, Roberto A. $R$ de. Os filhos da flecha do tempo: pertinência e rupturas. Brasília: Letraviva, 2000.

AMARAL , Francisco. Espírito e técnica romanos no Direito Ambiental brasileiros.

Revista Brasileira de Direito Comparado. Rio de Janeiro. Instituto de Direito Comparado Luso- brasileiro, 1993.

ANTUNES, PAULO DE BESSA. Direito Ambiental. Lumen Juris. 5 ed. 2001.

BARBOSA, Derly. Dialética e a educação: a formação do sujeito interdisciplinar. In: Revista Unifieo, Osasco, v.1, nº 2, p. 121-130, dezembro, 1999.

BOURDIEU, Pierre. “ A doxa e a vida cotidiana: uma entrevista”. In ZIZEK, S. (Org.) Um mapa da ideologia. Rio de Janeiro: Contraponta, 265-278, 1996.

BRASIL. Constituição da República Federativa do Brasil de ( 1988). Constituição da República Federativa do Brasil. Brasília, DF, DF: Senado; 1988,

BRASIL. Lei no 9.795, de 27 de abril de 1999. Lei de Educação Ambiental.

CARVALHO, I. C. M. O ambiental como valor substantivo: uma reflexão sobre a indentidade da educação ambiental. In: Sauvé, L. Orellana, I. Sato, M. Textos escolhidos em Educação Ambiental: de uma América à outra. Montreal, Publications ERE-UQAM, 2002, Tomo I, pp 85-90 (versão em português).

CARVALHO, I. C. M. A invenção do sujeito ecológico: narrativas e trajetórias da educação ambiental no Brasil. Porto Alegre: Ed. Universidade/ UFRGS, 2001.

DIAS, GENEBALDO FREIRE. Atividades Interdisciplinares de Educação Ambiental. Global. 1994. 


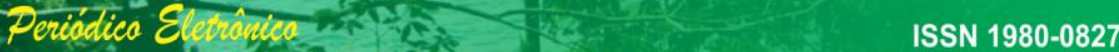

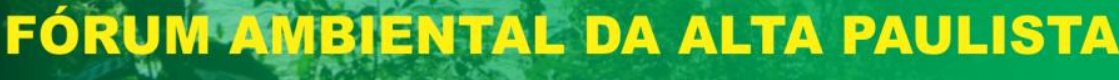 \\ V. 07, N. 05, 2011 - Categoria: Artigo Completo \\ Instituição Organizadora: ANAP - Associação Amigos da Natureza da Alta Paulista}

DEMO, Pedro. Educação e qualidade. Campinas, Papirus,1994.

FREIRE, Paulo. Pedagogia da autonomia: saberes necessários à prática educativa. São Paulo: Paz e Terra, 2002.

GALLO, Silvio. Transversalidade e educação; pensando uma educação não disciplinar. In. ALVES, N. \& GARCIA, R. L. (Org.). O sentido da escola. ( $2^{a}$ ed) Rio de Janeiro: DP\& ${ }^{-}$Editora, 2000.

GOMES, F. Araújo. Pesquisa e análise de conteúdo(mass media). Âmbito Cultural Edições, 2003.

GUTIÉRREZ-PEREZ, J. Por uma formação dos profissionais ambientalistas baseada em competências de ação. In: SATO, M.; CARVALHO, I. Educação Ambiental: pesquisa e desafios. Porto Alegre: Artmed, 2005.

HÖFLING, E. M. Estado e políticas (públicas) sociais. Cadernos Cedes, ano XXI, nำ 55, novembro, 2001.

LEFF, E. Saber Ambiental: sustentabilidade, racionalidade, complexidade, poder.

Petrópolis: Vozes, 2001.

LIBÂNEO, J. C. ; OLIVEIRA, J. F. de. TOSCHI, M. S. Educação Escolar: políticas, estrutura e organização. São Paulo: Cortez, 2003.

LOUREIRO, C. Trajetória e fundamentos da educação ambiental. São Paulo: Cortez,2004.

MILARÉ, Edis. Direito do Ambiente. São Paulo: Revista dos Tribunais, 2004.

MORIN, Edgar. Os sete saberes necessários à educação do futuro. São Paulo: Cortez, Brasília, DF: UNESCO, 2005.

MORIN, E. Os sete saberes necessários à Educação do Futuro. 4. ed. (Trad. Catarina E. F. da Silva e Jeanne Sawaya) São Paulo/ Brasília: Cortez/ Unesco, 2001. 118p.

MORALES, Angélica Góis Muller. A formação do profissional educador ambiental: reflexões, possibilidades e constatações no curso de especialização da UFPR. Curitiba: 2007.

NÓVOA, A. Professor se forma na escola. Portugal: Publicações Dom Quixote Ltda., 1995.

RATTNER, Henrique. Desenvolvimento sustentável - tendências e perspectivas. In MAGALHÃES, Luiz Eduardo de. A questão ambiental. São Paulo: Terragraph, 1994. p. 33 a 46. 


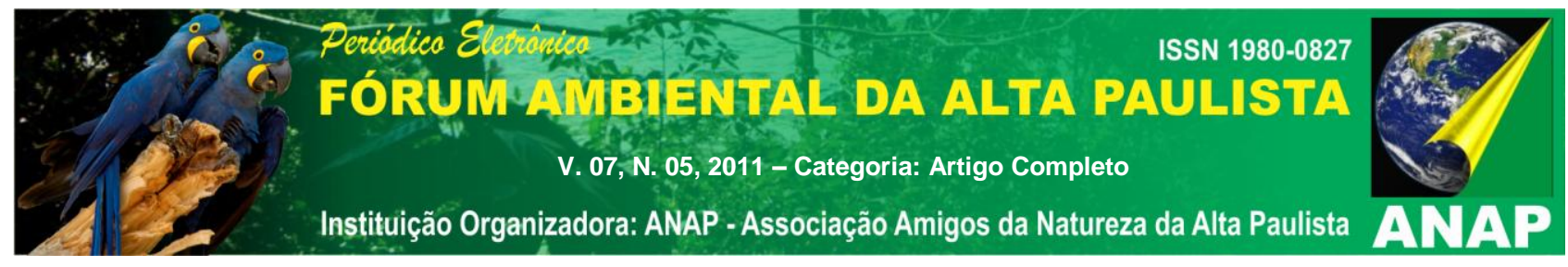

REIGOTA, Marcos. Meio Ambiente e Representação Social. 3ed. São Paulo: Cortez, 1998.

REIGOTA, M. O que é educação ambiental. São Paulo: Brasiliense, 2001.(p21) .

REIGOTA, M. Meio Ambiente e Representação Social. 5ª ed. São Paulo: Cortez, 2002.

SANTIAGO, Ana Rosa F. Projeto político-pedagógico da escola: desafio à organização dos educadores. In: VEIGA, Ilma Passos Alencastro (org.). Projeto PolíticoPedagógico: uma construção possível. 2. ed. Campinas: Papirus, [s.d]

SATO, M. Educação Ambiental. São Carlos, RiMa, 2004.

SILVA, JOSE AFONSO DA. Direito Ambiental Constitucional. Malheiros. 4a ed. 2002.

VERNIER, J. Meio Ambiente. Editora Papirus. Campinas-SP. Tradução: Marina Appenzeller. 132p, 1994.

ZABALZA, Miguel A. O ensino universitário: seu cenário e seus protagonistas. Porto Alegre: Artmed, 2004. 